\title{
Exploring Two Cases of Amazigh Maintenance and Shift in a Moroccan Higher Education Institution
}

\author{
Abdelaziz Ait Taleb \\ University Ibn Zohr, Agadir \\ aziztaleb82@gmail.com \\ Mohamed Elghazi \\ University Ibn Zohr, Agadir \\ m.elghazi@uiz.ac.ma
}

DOI: http://doi.org/ 10.36892/ijlls.v3i2.609

\begin{tabular}{ll}
$\begin{array}{l}\text { Received: } \\
\text { 25/05/2021 }\end{array}$ & Abstract \\
& The study of Language Maintenance and Shift (LMS) is mainly concerned with \\
Accepted: & "habitual use" of these varieties. This paper focuses on investigating two cases \\
28/06/2021 & of LMS among native Amazigh-speaking youngsters who were enrolled at a \\
& higher education institution in the city of Agadir, Morocco. With regard to their \\
\hline Keywords: & linguistic background, the two cases are bilingual in an Amazigh variety \\
Language & (Tashlhit) as their mother tongue and Moroccan Arabic (Darija) as their L2. \\
Maintenance and & The purpose of the study is to explore the possible determinants of LMS among \\
Shift, Amazigh, & these two cases by exploring both their language choice patterns and social \\
Moroccan Arabic, & networks in particular language use domains (family and school). The \\
domains, social & instruments utilized to collect data included 'natural speech' recordings, self- \\
networks. & report questionnaires, and interviews. The collected data were analyzed and \\
& interpreted in the light of Domain analysis and Social Network theories. The \\
& results revealed inconsistency in the case studies' patterns and determinants of \\
& LMS. Accordingly, the study concluded by recommending adopting more \\
& comprehensive models to better comprehend the dynamics of LMS in \\
indigenous settings.
\end{tabular}

\section{INTRODUCTION}

The rapid rate of globalization has posed more serious challenges and threats to indigenous and minority languages. These challenges have triggered more awareness and concern among sociolinguists about the need to preserve the world's linguistic and cultural diversity. In fact, the study of Language Maintenance and Shift (LMS) has been at the heart of both macro and micro sociolinguistics research for several decades. The foundations of research in this field are principally attributed to the works of Fishman $(1964,1965)$ and other pioneers in the field, including Gal (1979) and Dorian (1981).

The main concern of LMS research is to develop theories and models that could explain and predict LM and LS processes in different contact settings; yet, migrant and indigenous settings were not equally attended by researchers. Early research in the field focused more on migrant settings in Europe and United States while indigenous ones did not receive equal attention. In fact, the differences between these two types of settings and the intergroup differences within each type minimize the generalizability of research findings in this area.

Furthermore, the lack of conformity across groups implies that each language contact setting is unique in terms of the variables involved in shaping individuals' language behavior. 
The present study investigates the shifting process from an Amazigh (AM) variety (Tashlhit) to Moroccan Arabic (MA) among a young population of bilingual Moroccan students. The language contact setting in which the present study was conducted is a good example of such indigenous settings that have not been sufficiently attended by researchers.

\section{LITERATURE REVIEW}

The issue of LMS in the present study is informed by the Domain Analysis theory (Fishman,1965) and the Social Network Analysis (Milroy, 1987; Stoessel, 2002). These models are situated within the scope of the sociology of language approach, which is concerned with the study of the relationship between language and society.

\subsection{Domain analysis research}

Fishman (1965) defined 'domain' as " a socio-cultural construct abstracted from topics of communication, relationships between communicators, and locales of communication, in accord with the institutions of a society and the spheres of activity of culture, in such a way that individual behavior and social patterns can be distinguished from each other and yet related to each other" ( p.75).

This definition implies that the domain construct is built around three key elements: interlocutors, topics, and locales, with the latter comprising both time and place. In other words, research at this level is concerned with investigating variables involved in particular situations; these refer to where, when, and with whom a particular language is used. According to Pauwels (2016), the main domains that have received attention in the field of LSM are (1) the family/ home domain, (2) the friendship domain, (3) the religious domain, (4) the domain of secular societies and clubs, (5) the work domain and (6) the educational domain.

Domain analysis has enabled an in-depth description of LMS processes across various domains; it has allowed researchers to distinguish domains that are vulnerable from others that are resistant to language displacement in different language contact situations. For instance, in a study of a bilingual Puerto Recan community in New Jersey, Fishman et al. (1971) found out that there is a general tendency among the community members to use L1 in private domains (family, friends, church), whereas English (L2) is used in public domains like school, work and sometimes church. This diglossic pattern in which two languages are used to serve different functions was viewed by Fishman et al. (1971) as the main factor that would enable stable bilingualism. This implies that the languages or language varieties that are associated with predictable domains are likely to be maintained. Further, Fishman et al. (1971) 's study has highlighted the significant importance of role relations within the domain and how they influence language choice. For instance, the parent-child relation may dictate the use of a particular language that is different from the language that an employer-employee relationship would necessitate.

Several other studies have employed Fishman's (1972) domain analysis in investigating patterns of language shift and maintenance. One of the most serious discussions and analyses of the domain concept was Greenfield's (1972) investigation of language choice patterns among the bilingual Puerto Ricans in New York City. The study's findings revealed that Spanish was regularly used in family discourse, whereas English was used in education and employment. These results imply that the respondents tend to maintain their mother tongue in intimate domains.

Leo and Abdullah (2013) have adopted Fishman's domain analysis model to determine the dominant language choice of Tamil Christian youths in Malaysia based on their patterns of language choice and use in the domains of family, friendship, and religion. They also examined the underlying factors that govern the youth's language choice patterns in the selected domains. Questionnaires and interviews were used to collect data about the 60 multilingual respondents 
in this study. The study's findings showed the predominance of English over Tamil and Bahasa Malaysia due to such factors as language use domains, the interlocutors' language proficiency, the speakers' language attitudes, and their sense of social solidarity and social identity.

Generally, Domain analysis has provided valuable insights into the processes of bilingualism and language choice (Fishman, 1965). This analysis helped clarify the intertwined relationship between compound and coordinate bilingualism as two related phases along a continuum instead of the traditional view that classified them as two distinct and exclusive stages. In other words, a group of bilingual speakers may begin as compound bilinguals in multilingual contexts with each language assigned to particular domains. With time, this type of bilingualism may develop into coordinate bilingualism where far greater domains overlap occurs. Moreover, domain analysis has contributed to a better understanding of how the patterns of bilingual acquisition and functioning (compound vs. coordinate bilingualism) operate under different socio-cultural conditions.

\subsection{Social Network research}

The Social Network Analysis (SNA) is the second sociological theory adopted in this study to investigate other sociological variables, namely the relationship between individuals' social networks and their language behavior. The SNA is situated within the interactionist approach to the study of language and multilingualism.

The SNA is currently considered one of the significant new approaches to studying LMS processes that emerge from Milroy's (1987) work on language and social networks. The theory's focal point is the investigation of the relationship between the individual's social environment and his language attitudes and language behavior by analyzing the types of connections that individuals have in a community. The purpose is to describe and explain how language use patterns vary across individuals who live in the same area. Stoessel (2002) argued that this theory's main advantage is that it provides a framework within which it has become possible to carry out a more fine-grained analysis of language use in specific social networks instead of relying on general societal factors.

Several studies have employed SNA to the study of LMS issues in both migrant and indigenous settings. Milroy (2001) investigated the impact of social networks on language change by measuring the density of her consultants' social networks then correlating them against their use of some speech elements, particularly the phonological ones. The study's findings revealed a positive correlation between the two; the subjects tend to use low-status speaking methods when interacting with close people to express social solidarity. Milroy (2002) concluded that low-status varieties are maintained thanks to the pressure of kin and friendship networks. She added that LMS processes are subject to the same pressure, insisting that individuals or groups with weak uniplex ties to L1 speakers are likely to shift to a dominant language.

Stoessel's (2002) case study of ten immigrant women in the US has been widely cited in the social network analysis research. The study explored the possible association between social networks and immigrant women's language choice patterns in the US. The study's findings revealed a strong association between the degree of language maintenance and the prevalence of L1 contacts in the subjects' entire network. Besides, the study showed an association between language maintenance and the proximity of L1 speakers. The closer the speaker is to L1 contact, the more likely he is to maintain his language. Further, the results showed that the strength of the contacts' relationships with the home country network is another potential factor associated with language maintenance. However, the researcher did not find any clear relationship between the frequency of contact and language use.

Other studies have confirmed the predictive power of social networks in the process of LMS. Wei (1994) found that the ethnic composition of a network has a significant influence on individuals' language choice patterns than such demographic variables as age and gender. 
Similarly, Dashti et al.(2004)'s study investigated the shifting process from Frasi to Kuwaiti Arabic among members of two Kuwaiti Ajan families. The results revealed that the social network factor in the process of LMS held more significance than other factors like migration, religion, intermarriage, age, and gender.

Chabah (2006) examined the impact of social networks on L1 maintenance across generations among the Kabyle community (An Algerian Berber variety speakers) in Montreal. The study's findings revealed that the more the respondents' social networks are extended to L1 contacts, the more they maintain and transmit the Kabyle variety to children. It was also found out that having L1 contacts among friends is correlated with the maintenance of L1 and its transmission to children: the more these contacts are numerous, the more the respondents maintain their L1 and transmit it to children.

As the studies cited in this section reveal, much research in this area has focused on case studies in migrant settings with less attention to indigenous and territorial settings. The present study investigates the significance of social network analysis for the study of LMS processes in an indigenous setting where AM and MA are in contact.

\section{CONTEXT OF THE STUDY}

The linguistic situation in Morocco is characterized by the interaction of various languages and language varieties (Boukous, 1979, 1995; Bensoukas,2010; Ennaji, 1991; Zouhir,2014). This linguistic mosaic includes two official national languages (Arabic and Amazigh) and a few foreign ones (mainly French, Spanish, and English). This linguistic heterogeneity has resulted in various multilingualism patterns that have posed challenges with respect to maintaining and managing linguistic diversity.

The present study investigates some patterns and determinants of the shifting process from an AM variety (Tashlhit) to MA in Agadir- the capital city of one of the biggest Amazighophone regions in Morocco. The target population of the study are educated youngsters who have been brought up in Agadir city and who are bilingual in Tashlhit variety, as their mother tongue, and MA as their L2.

\section{METHODOLOGY}

\section{Research objectives \& questions}

The ultimate goal of this study is to contribute to LMS research in indigenous settings by exploring how two major types of sociological variables impact LMS processes. The investigated sociological variables in this study are language use domains and individuals' social networks. In concrete terms, the study's first objective is to characterize the youngsters' patterns of AM maintenance and shift across domains of family/home, school, and friendship. The second one is to explore the sociological determinants of AM maintenance and shift as determined by domain-related variables and youngsters' social networks.

The objectives above constitute the landmarks of this study's general scope as reflected in the research questions outlined below:

- What are some patterns of AM maintenance and shift across the domains of home, school, and friendship?

- What are some sociological determinants of AM maintenance and shift as determined by language use domains and individuals' social networks?

Design

The research design adopted in this study is a 'mixed-methods research' in which quantitative and qualitative elements are integrated. The choice of mixed-methods design is driven by its research potentials as it allows researchers to approach a research problem in 
multiple ways (Creswell \& Clark,2018). Accordingly, the present study employed a triangle method of data collection, which includes recorded conversations, self-report questionnaires, and interviews. Therefore, the speakers' language choice patterns that emerged in the recorded conversations were described and interpreted in the light of the self-report questionnaire and interview data.

\section{Research Procedure}

During the process of recording the participants' 'natural speech', the researcher has acted the role of a non-participant observer by requesting the two case studies to record extracts of their conversations with other Tashlhit-speaking interlocutors, namely their family members (parents, siblings, grandparents), classmates, roommates, and friends. Some procedures had been taken to ensure a high degree of objectivity and authenticity. At the beginning, the researcher promised that the conversers' identities would be kept anonymous and that the recorded conversations would be used solely for research purposes. Yet, the two cases were not informed about the issue under study to maximize the validity of the collected data; for example, had they known that the study is about AM shift and maintenance, their language behavior could have been affected as they engage in conversations.

The use of this method has many advantages. First, it is a less obtrusive way of collecting data in the sense that the researcher did not intervene in this process. Second, the non-participation of the researcher has helped in collecting data with a high degree of spontaneity and authenticity. The volunteering cases have recorded natural exchanges in intimate contexts that were difficult for the researcher to access. These include speech events that took place between roommates in their dorms at the boarding school, the conversations between siblings at home, and the conversations between siblings and their parents.

To attain a balance between the need for "natural" and authentic data and the concern about ethical issues related to the privacy of the recorded speakers, the volunteers were instructed to record the conversations as they occur before they get permission to share them with the researcher. In addition, the researcher insisted that volunteers should record the conversers only when they engage in nonprivate topics like studies, a football match, a TV program, etc.

After the instructions were made clear for each volunteer participant, the first wave of recording conversations was launched. This first wave was meant for trial purposes to check for issues of validity and reliability. Following this, all the volunteers submitted their collected recordings. Then, they have been checked and evaluated by the researcher in terms of their relevance, naturality, and voice quality. Afterward, the volunteers were invited to discuss some issues that had emerged during the first wave of data collection. For instance, some volunteers reported that their interlocutors disapprove of sharing their recorded speech. The researcher then explained that the interlocutors' disapproval should be respected and would never be considered an issue. Eventually, the volunteers started a new wave of data recording conversations in as many contexts and domains as possible.

In the following section, the data collected through this technique is described, analyzed, and interpreted in the light of domain analysis and social network theories. First, a description of the conversational context (interlocutors, language use domain, and topic) will be provided. Then, an analysis of language choice patterns will follow. This is supported by data obtained from the questionnaire and interviews. Finally, interpretations of the language behavior of individual case studies will be made in the light of the related theories.

\section{RESULTS AND DISCUSSION}

Case study 1

The first case study that was investigated was an eighteen-year-old female student at CPGE classes. FZ was raised in a family of AM origin in Agadir city. She is bilingual in AM 
and MA with a tendency to use MA more in her daily communication. This informant managed to record conversations in various home and school settings. Her language behavior patterns and determinants are described across domains of language use.

\section{The family domain}

The first recorded interaction involves speakers of two different generations (siblings and their mother). According to FZ, all her siblings can speak Tashlhit variety fluently since it is their mother tongue. This extract is part of an ongoing conversation between FZ, her brother (AB), and her mother. Apparently, these family members are at home watching a TV sports program because their talk is disturbed by the voice of a TV program presenter.

The first interaction is an exchange between the siblings (FZ \& AB) about some Moroccan football players at the Diaspora (Netherlands), with a minor contribution from the mother. $\mathrm{AB}$ was telling his sister about the tragedy of a football player who had been in a coma for two years. Later, FZ switched the conversation by commenting on her mother, who was busy preparing a meal. FZ advised her mother not to put hot food in plastic pots as this might cause some health problems. The mother responded by saying that the food had been cooled down before being placed in the pot.

Throughout these exchanges that took place at home, MA (Darija) has been the sole variety of communication between all the interlocutors. During the interview, which was eventually conducted with FZ, she reported that all her family members speak Tashlhit variety natively; yet, as she explained, the family started using Darija at home since they had moved to a new neighborhood ten years before. As she explained, the inhabitants of the new neighborhood are mostly MA speakers.

The interlocutors' language behavior, which is characterized by the use of MA (Darija) throughout this speech event, indicates that this family is undergoing a shifting process to MA in the home domain. Seemingly, this language choice behavior is habitual since the interlocutors did not switch to Tahlhit variety even when the topic of discussion was switched. The shift in this domain is generally considered the last bastion of language maintenance (Coulmas, 2005).

However, FZ still maintains a native-like AM proficiency, as observed during the interview and during her interactions with some of her AM-speaking classmates. As FZ confirmed during the interview, the main reason behind this shift to MA in the home domain is her family's movement to a new neighborhood that MA speakers dominate. This is supported by Fishman (1965) 's argument that the desire to identify with the new community is likely to trigger this shifting process, especially among the younger generation who are more vulnerable to shift to L2 than the elderly.

\section{The school domain}

The second recorded conversation involves FZ with a group of AM-speaking female students in the boarding school. Although the interlocutors' identities were kept private, one can distinguish between four interlocutors with different voices. According to FZ, some interlocutors are from a village in the province of Tiznit, while others are from the Chtouka region. Despite the regional differences, all the interlocutors speak Tashlhit variety in a mutually intelligible way.

It was the second day of Ramadan, and these students were around the table waiting for dinner to be served. They are engaged in a conversation about their 'exceptional' experience of the first day of Ramadan and how some of them found it difficult to spend Ramadan away from their families. First, the interaction opened with the talk of one of the group members who was telling FZ about the quality of food served the previous day (FZ spent the first day of Ramadan with her family, who lives in a nearby neighborhood). The interaction between the 
two has been frequently interrupted by other group members who seemed satisfied with the service. However, some criticized the misconduct of some students during meals.

It is noticed that the four speakers maintained Tashlhit variety throughout the conversation even though they came from different cities. More importantly, FZ has maintained Tashlhit in her interactions with her peers in the boarding school, although she does not use it at home with her family. The fact that her peers are originated in rural regions might be an essential factor in their maintenance of L1. Because they constitute "the majority" in this group, they seem to exert a strong influence on FZ's language behavior. That is to say, FZ found herself in a community of AM-speaking students where the use of AM is necessary to gain acceptance from the group (Fishman, 1965).

Besides, the ties that relate her to her mates at the boarding school appear to have a crucial role in maintaining her mother tongue in the school domain. This can reinforce the social network theory (Milroy,1987; Stoessel, 2001), which stresses the importance of one's social networks in shaping his language behavior; the more a bilingual speaker is attached to L1 speakers in a particular domain, the more likely he maintains L1 in that domain.

\section{Case study 2}

$\mathrm{R}$, a CPGE student, is the fourth case study whose language behavior was explored in this analysis. She exhibited a high bilingual proficiency in both AM and MA. R was born and brought up in a nuclear family in Agadir city. This informant showed a high sense of cooperation and commitment as she has provided rich data for this study, which included recorded conversations with her roommates, classmates, and family members. She has also recorded some interactions that took place among her family members. These varied data helped enlighten other dynamics of AM maintenance and shift among youngsters who have been brought up in urban areas.

\section{The school domain}

The first extract involves three students: two AM speakers and a MA one. The three had been in their boarding school dormitory before they moved out to the campus yard. In the first exchange, the three roommates were talking about the criteria and procedures of accessing engineering schools. The language of interaction throughout this exchange was Darija (MA). Later, the two AM speakers moved to the basin to wash their hands. At this moment, they switched to a worrying issue related to the water cut in the boarding school and how the female department is the one that suffers more than the male one. This topic-switch was paralleled with a shift in language as the two speakers used Tashlhit solely when they complained about this problem. Afterward, the three roommates moved altogether to the classroom as they were going to have an afternoon class. Again, being together means a switch back to Darija (MA) as they were walking and talking about an upcoming class session they would have that afternoon. The interaction ended as these roommates met their classmates before they got into the classroom.

It seems that the two AM-speaking students tend to maintain AM when they are together but shift to MA in the presence of a non-AM speaker. This factor seems to be a powerful one in language shift among AM-speaking students in boarding school.

In the second extract, which has been apparently recorded at a different time, $\mathrm{R}$ and her AM-speaking roommate engaged in a conversation about the approaching Ramadan and how they expected it to be an exceptional experience in the boarding school. Throughout this exchange, Tashlhit has been the sole variety of interaction. $\mathrm{R}$ started by asking her interlocutor about her home village location; $\mathrm{Z}$ explained that her home is located in the suburbs of Taroudant and that it takes her three taxis to get there. Then, they expressed their worries about their first experience of spending Ramadan away from their families. Eventually, some study 
difficulties the two speakers face in the Physics course were brought up for discussion. Here, a shift to MA has occurred as the speakers converse about this topic.

The special feature of the linguistic behavior of this case study in the school domain is its influence by the topic of conversation. Apparently, Tashlhit tends to be maintained when the topic is related to intimate issues (home, Ramadan,), while Darija is the variety of conversing about studies-related issues. These students have probably developed the habit of using Darija in the school context as they are usually in contact with students from different linguistic backgrounds. Besides, sharing the same room with a student from AM background appears to influence the students' maintenance of their L1. In the case of R and Z, their regional differences did not prevent them from maintaining AM in intimate interactions. Also, the mutual intelligibility between the regional varieties of Tashlhit contributes to the maintenance of this variety by students from different Souss regions.

\section{The family domain}

The third recorded extract depicts conversations between members of R's extended family. This gathering includes $\mathrm{R}$ herself, her mother, two aunts, grandmother, and cousins. It was a very intimate family gathering in which several issues were brought up. Remarkably, Taslhit was the sole variety of interaction by all the speakers in this extract;

In the beginning, the family members were discussing an employment issue- whether working for a bank is acceptable from the Islamic perspective. But, then, the topic has been switched to the general problems that today's youth face in finding an appropriate job. The grandmother, who seemed to dominate the talk, has given her grandchildren some tips of advice on being smart and determined. She supported her advice with some AM wisdom sayings to encourage her grandchildren to work hard. Eventually, the whole family members' attention was directed towards R's little cousin, Rayan, who had just started bubbling some Tashlhit words as some other family members were playing with him. This has created a fun atmosphere within the family gathering.

This extract provides important insights that can help understand R's language choice patterns in relation to the linguistic environment at home and her family language policy. First, $\mathrm{R}$ and other family members' language behavior is characterized by total AM maintenance throughout all the interactions that were about various topics. This implies that in this case, neither the interlocutor nor the topic has induced a change in language choice. Second, this family represents an excellent example of the intergenerational transfer of the mother tongue. We have noticed that the speakers from three generations (grandmother, mother/ aunts, cousins) have maintained Tashlhit throughout their exchanges, showing a native-like proficiency of this variety. The little boy's bubbling of Tashlhit words may indicate a continuous family language policy of transferring the mother tongue to future generations. Third, living with grandparents is likely to provide more chances for AM maintenance than living in a nuclear family. Finally, the family relatives' network, represented in aunts and cousins, appears to be an essential variable in AM maintenance. According to R's responses in the questionnaire, she reported that her contact with family relatives is frequent and that Tashlhit is usually the means of interaction in such family gatherings.

The fourth extract is a relatively long talk between $\mathrm{R}$ and two of her cousins. It was the religious occasion of the Al-Fitr feast when family relatives exchanged visits. The talk, which was entirely carried out in Tashlhit, was about the career of one of the cousins (a female one) whose job was related to web design and development. The other cousin (a male one) seemed to be more knowledgeable about that field. The two cousins dominated this conversation as they exchange information about this field; they discussed the importance of self-development to keep updated about the innovations in this field. However, $\mathrm{R}$ did not contribute much to this interaction; she simply interrupted from time to time by asking her cousins some questions 
about that field. Along with this interaction, some women were sitting nearby as their voices were pretty audible, were also chatting in Tashlhit variety.

This extract provides more information about the possible relationship between R's language behavior and the type of family contacts and environment in which she has been brought up. R's family relatives seem to have a noticeable tendency to maintain Tashlhit variety in their interactions regardless of the topic of discussion. It is crucial to note that the topic of discussion, which typically involves special technical jargon, did not induce a change in the interlocutors' language choice patterns.

The sixth extract, however, is distinctive in terms of the language behavior of the speakers. R was helping her younger sister with some Physics homework. They were alone in a room discussing the tasks and having some fun. $\mathrm{R}$ was trying to explain to her younger sister some Physics concepts that she did not seem to grasp. Unexpectedly, Darija was the main variety that has been used throughout this interaction between the two sisters, with a little word borrowing from French by $\mathrm{R}$ to refer to specific concepts.

Two important contextual variables are worth mentioning here: the topic of discussion and the absence of other family members. The topic of conversation (studies) may have been the trigger of the change in R's language behavior. Discussing Physics issues requires special jargon that the two speakers may not know in AM as this language is not taught in secondary education. The second possible factor that can explain R's language behavior is the strong influence that the interlocutor (the younger sister) exerts on the speaker's language behavior. Usually, younger generations tend to lose their L1 in particular domains more than older ones. Therefore, $\mathrm{R}$ might have developed the habit of addressing her sister in Darija rather than Tashlhit, especially in the absence of other family members. This is compatible with both the questionnaire and interview data. $\mathrm{R}$ reported that although she tends to maintain Tashlhit in the home domain when she interacts with most family members and relatives, she usually addresses her younger sister in Darija. This can be attributed to intergenerational differences as older generations tend to maintain AM more than the younger ones.

\section{CONCLUSION}

Exploring the two cases' language behavior in different language use domains and settings has yielded some insightful implications regarding some sociological determinants of AM maintenance and shift among youngsters in Agadir city. The data revealed that the language choice patterns of the first case study were affected by three main factors: the place of settlement (the neighborhood), the social networks at school, and the desire to identify oneself with a particular group to which one belongs or wants to belong to. Another possible factor is the individual's attatchment to his own language and cultural identity (Al-Saggaf,, Kader, Alias, \& Abdul Raof, 2020) As for the second case, the main determinants of AM maintenance and shift seemed to be the family language policy and the frequent contact with AM family relatives networks. Further, the interlocutor's generation seems to be another inducer of the shift towards MA; R tended to shift to MA when she interacted with her younger sister, who did not seem proficient AM. This implies that individual bilinguals exhibit inconsistent patterns of AM maintenance and shift depending on a variety of factors. Therefore, a deeper understanding of the dynamics of LMS in indigenous settings requires the development of more comprehensive models that would consider various factors that interact in indigenous contact settings.

\section{REFERENCES}

AL-Saggaf, M., Kader, F. F. ., Alias, A. N. I. ., \& Abdul Raof, N. A. . (2020). Level of Attachment of Malaysian TESL Students Towards Their Cultural Identity. 
International Journal of Language and Literary Studies, 2(4), 63-82. https://doi.org/10.36892/ijlls.v2i4.458

Bensoukas, K. (2010). Language policy and mother tongues in Morocco: A linguistic human rights perspective. In Y. El Kirat el Allame (Ed.) Globalization and mother tongues in Africa, 135-152. Editions \& Impressions Bouregreg.

Boukous, A. (1979). La situation linguistique au Maroc. Europe, 57(602), 5.

Boukous, A. (1995). La langue berbere: maintien et changement. International Journal of the Sociology of Language, 1995(112), 9-28.

Chabah, M. (2006). Rôle des réseaux sociaux dans le maintien et la transmission de la langue maternelle en situation d'immigration: cas de la communauté kabyle de Montréal. (Doctoral dissertation) Université du Québec à Montréal. https://archipel.uqam.ca/3453/1/M9558.pdf

Coulmas, F. (2005). Changing language regimes in globalizing environments. International Journal of the Sociology of Language, 2005(175-176), 3-1 https://doi.org/10.1515/ijs1.2005.2005.175-176.3

Dashti, A. M., Qutb, K. A., Al-Khalil, A. M., Al-Naboodah, H. M., \& Basheer, A. (2004). Language Maintenance Or Shift?: An Ethnographic Investigation of the Use of Farsi Among Kuwaiti Ajams: a Case Study. Kuwait University.

Dorian, N. (1981). Language death: The life cycle of a Scottish Gaelic dialect. Philadelphia: University of Pennsylvania Press

Ennaji, M. (1991). Aspects of multilingualism in the maghreb*. International Journal of the Sociology of Language, 87(1), 7-26. https://doi.org/10.1515/ijsl.1991.87.7

Fishman, J. (1964). Language maintenance and language shift as a field of inquiry. Linguistics, 9, 32-70.

Fishman, J. (1965). Who speaks what language to whom and when? La Linguistique, 1(2), 6788. https://www.jstor.org/stable/30248773

Fishman, J. A., Cooper, R. L., Newman, R. M., \& Ma, R. (1971). Bilingualism in the Barrio (Vol. 1). Indiana University. Fishman, J. A.(1972) The sociology of language: an 
interdisciplinary social science approach to language in society. Rowley, MA: Newbury House.

Gal, S. (1979). Language shift: Social determinants of linguistic change in bilingual Austria. New York: Academic Press.

Greenfield, L. (1972). Situational measures of normative language views in relation to person, place, and topic among Puerto Rican bilinguals. In J.A. Fishman (Ed.). Advances in the sociology of language (17-35). Vol. 2. The Hague: Mouton.

Leo, A. R., \& Abdullah, A. N. (2013). Language Choice and Use of Malaysian Tamil Christian Youths : A Survey. Frontiers of Language and Teaching, 4, 149-166.

Milroy, L. (1987). Language and social networks. Oxford: Blackwell.

Milroy, L. (2001). Bridging the micro-macro gap: Social change, social networks, and bilingual repertoires. Theories of maintenance and loss of minority languages, 39-64.

Pauwels, A. (2016). language Maintenance and Shift. Cambridge University Press.

Stoessel, S. (2002). Investigating the role of social networks in language maintenance and shift. International journal of the sociology of language, 2002(153), 93-131.

https://doi.org/10.1515/ijs1.2002.006

Wei, L. (1994). Three generations, two languages, one family: Language choice and language shift in a Chinese community in Britain (Vol. 104). Multilingual Matters.

https://www.jstor.org/stable/4168685?seq $=1$

Zouhir, A. (2014). Language Policy and State in Morocco: The Status of Berber. Digest of Middle East Studies, 23(1), 37-53. https://doi.org/10.1111/dome.12039

\section{$\underline{\text { AUTHORS' BIO }}$}

Abdelaziz Ait Taleb is a PhD candidate at the Faculty of Letters and Human sciences at Ibn Zohr University, Agadir. He is interested in Applied linguistics (FL teaching \& learning) and the issues language contact and language choice.

Mohamed Elghazi is a Senior professor of Linguistics and the Sociology of Language at Ibn Zohr University, Agadir, Morocco. He is interested in modern theoretical linguistics (syntax), and the issues of multilingualism, language policy and language change. 